\title{
Comparison of Somatotype of Physically Active Punjabi Men of Different Age Group
}

\author{
Nishibha Thapliyal and Ashok Kumar
}

\begin{abstract}
Aim: The aim of the study was to observe and compare the somatotype of physically active Punjabi men according to different age group. Method: One hundred $(\mathrm{N}=100$, ) men with regular physical activity between the ages 20-40 years were randomly selected and divided into four group on the basis of their age. Each subject was measured for anthropometric parameters after taking valid consents. Results: The mean age, height weight and BMI of all subject $(\mathrm{N}=100)$ was $34.1 \pm 5.0$ years, $172.7 \pm 3.7 \mathrm{~cm}, 71.6 \pm 5.7 \mathrm{~kg}$ and $24 \pm 1.8 \mathrm{~kg} / \mathrm{m}^{2}$ respectively. The mean somatotype of men belonging to Group-1( 20- 25 years), Group-2(26-30 years), Group-3(31-35 years) and Group-4 (36-40 years) was 2.08-4.14-3.05, 2.93-5.55-1.78, 3.79-6.55-1.83 and 3.91-5.74-0.84 respectively. Conclusion: The results indicate the dominance of mesomorphy in all age groups of physically active Punjabi men, which is an important component that characterizes muscularity due to regular physical activity. The age Group 30-35 yrs (6.55) showed the highest mesomorphy values. An increasing trend in endomorphy and mesomorphy was seen from age Group 1 (20-25yrs) to Group 3 (31-35yrs). Endomorphy which is characterized by fat components was found to high in middle age groups of 30-40 years leading to the conclusion that a change in frequency, intensity or type of physical activity may be needed.
\end{abstract}

\author{
Nishibha Thapliyal \\ Ph.D. Scholar \\ Department of Sports Science \\ Punjabi University (Patiala) Punjab, India. \\ Email: nishibhathapliyal@gmail.com \\ Ashok Kumar \\ Professor \\ Department of Sports Science \\ Punjabi University (Patiala) Punjab, India. \\ Email: akashokin@gmail.com
}

\section{Keywords: BMI, Somatotype, WHO}

DOI: $10.18376 /$ jesp/2019/v15/i1/111317

\section{Introduction}

Human body is the most complex area of research. It varies in size and composition from person to person. The quantification of human shape and composition was done by W. H Sheldon and he called it 'Somatotype'. Somatotype divided people into three major groups' endomorphs, mesomorphs and ectomorphs. Endomorphy is the relative fatness, mesomorphy is the relative musculo-skeletal robustness and ectomorphy is the relative linearity or slenderness (Heath \& Carter, 2002). There are many factors like gender, genetics, feeding habits and environment that affect human shape and size (Saranga et al., 2008; Reis et al., 2007). Somatotype is also seen to vary with change in physical activity as well. There is ample evidence indicating athletes have distinctive somatotype in accordance to the demands of the sports they are involved in (Rahmawati, et al., 2007; Carter 1970). There have been many studies on athletes and their somatotype but information about the non-athletic population is very less. Due to global rise in obesity and other lifestyle disorders, awareness about physical fitness and health related physical fitness among 
people has also increased (Heath 2012). There has been a significant increase in the population performing regular physical activity in parks, gyms and other recreational centers (Abercrombie et al 2008). Somatotype analysis nowdays has become important not only to understand one's own body type but also to identify groups at risks of developing cardiovascular diseases, hypertension and other metabolic disorder (Malina et al., 1997; Koleva et al., 2002) and hence people of all age groups have started becoming involved in some or the other typr of physical activity on a daily basis. The state of Punjab has the highest number of obese people in India (NFHS 2005-06), hence it becomes important to see if the population is in need of a higher physical activity environment in order to maintain good health in spite of a regular activity schedule. In the present study somatotype of physically active Punjabi men between the age ranges 20-40 years were observed.

\section{Materials and Method}

One hundred physically active men in the age ranged 20-40 years from Patiala, Punjab were selected for the study. The subjects were further divided into four groups on the basis of their age, Group-1 (20-25 yr, N=6), Group-2 (26-30 yr, N=8), Group-3 (31-35 yr, N=50) and Group-4 (36-40 $\mathrm{yr}, \mathrm{N}=36$ ). Subject who involved in some form of physical activity on a regular basis were only selected for the study. The selection was done on the basis of WHO's minimum moderate activity guidelines (WHO 2011). Random selection of samples was done in order to obtain genuine results and minimize bias. After the subjects were selected, each of them were measured for height, weight, BMI, skinfold measurements, girth measurements were taken after taking valid consents.

\section{Results}

The anthropometric characteristics and BMI of physically active Punjabi men are presented in Table 1.The mean age of participants in Group-1 (20-25 yr, N=6), Group-2 (26-30 yr, N=8), Group3 (31-35 yr, N=50) and Group-4 (36-40 yr, N=36) was 22.66 \pm 1.75 year, 28.25 \pm 1.43 year, $32.89 \pm 3.32$ year and $38.10 \pm 1.54$ year respectively (Table 1). The mean height of participants Group-1 (20-25 yr, N=6), Group-2 (26-30 yr, N=8), Group-3 (31-35 yr, N=50) and Group-4 (36-40 yr, $\mathrm{N}=36)$ was $173.00 \pm 5.21 \mathrm{cms}, 172.48 \pm 4.80 \mathrm{cms}, 172.19 \pm 3.47 \mathrm{cms}$ and $173.02 \pm 3.68 \mathrm{cms}$ respectively (Table 1). The mean body weight of participants Group-1 (20-25 yr, N=6), Group-2 (26-30 yr, N=8), Group-3 (31-35 yr, N=50) and Group-4 (36-40 yr, N=36) was 64.50 $\pm 3.20 \mathrm{kgs}$, $68.68 \pm 6.21 \mathrm{kgs}, 72.22 \pm 5.19 \mathrm{kgs}$ and $73.27 \pm 5.42 \mathrm{kgs}$ respectively (Table 1). The mean BMI of participants in Group-1 (20-25 yr, N=6), Group-2 (26-30 yr, N=8), Group-3 (31-35 yr, N=50) and Group-4 (36-40 yr, N=36) was $20.55 \pm 0.82 \mathrm{kgs} / \mathrm{m}^{2}, 22.97 \pm 1.44 \mathrm{kgs} / \mathrm{m}^{2}, 23.83 \pm 3.99 \mathrm{kgs} / \mathrm{m}^{2}$ and $24.48 \pm 1.73 \mathrm{kgs} / \mathrm{m}^{2}$ respectively (Table 1 ).

Table 1. Mean \pm SD of Age, height weight \& BMI of Physically Active Punjabi Men

\begin{tabular}{|c|c|c|c|c|c|}
\hline Group(s) & $\begin{array}{c}\text { Number } \\
(\mathrm{N})\end{array}$ & Age, (year) & Height (cm & Body weight (kg) & BMI $\left(\mathrm{kg} / \mathrm{m}^{2}\right)$ \\
\hline $\begin{array}{l}\text { Group -1 } \\
(20-25 \text { yr })\end{array}$ & 06 & $22.66 \pm 1.75$ & $173.00 \pm 5.21$ & $64.50 \pm 3.20$ & $20.55 \pm 0.82$ \\
\hline $\begin{array}{l}\text { Group - } 2 \\
(26-30 \text { yr) }\end{array}$ & 08 & $28.25 \pm 1.43$ & $172.48 \pm 4.80$ & $68.68 \pm 6.21$ & $22.97 \pm 1.44$ \\
\hline $\begin{array}{l}\text { Group - } 3 \\
(31-35 \text { yr })\end{array}$ & 50 & $32.89 \pm 3.32$ & $172.19 \pm 3.47$ & $72.22 \pm 5.19$ & $23.83 \pm 3.99$ \\
\hline $\begin{array}{l}\text { Group - } 4 \\
(36-40 \text { yr })\end{array}$ & 36 & $38.10 \pm 1.54$ & $173.02 \pm 3.68$ & $73.27 \pm 5.42$ & $24.48 \pm 1.73$ \\
\hline Total & 100 & $34.1 \pm 5.0$ & $172.7 \pm 3.7$ & $71.6 \pm 5.7$ & $24 \pm 1.8$ \\
\hline
\end{tabular}


The average somatotype of physically active Punjabi men of different age groups are presented in Table 2.The mean somatotype of men belonging to Group-1 (20-25 yr, N=6), Group-2 (26-30 yr, $\mathrm{N}=8$ ), Group-3 (31-35 yr, $\mathrm{N}=50$ ) and Group-4 (36-40 yr, $\mathrm{N}=36$ ) was 2.08-4.14-3.05, 2.93-5.55$1.78,3.79-6.55-1.83$ and 3.91-5.74-0.84 respectively (Table 2 ).

Table 2. Mean \pm SD of Somatotype of Physically Active Punjabi Men

\begin{tabular}{|c|c|c|c|c|}
\hline \multirow[t]{2}{*}{ Group(s) } & \multirow[t]{2}{*}{$\mathbf{N}$} & \multicolumn{3}{|c|}{ Mean \pm SD } \\
\hline & & Endomorphy & Mesomorphy & Ectomorphy \\
\hline $\begin{array}{l}\text { Group -1 } \\
(20-25 \text { yr })\end{array}$ & 06 & $2.08 \pm 0.81$ & $4.14 \pm 1.69$ & $3.05 \pm 0.64$ \\
\hline $\begin{array}{l}\text { Group - } 2 \\
(26-30 \text { yr })\end{array}$ & 08 & $2.93 \pm 0.88$ & $5.55 \pm 1.78$ & $2.29 \pm 0.74$ \\
\hline $\begin{array}{l}\text { Group - } 3 \\
(31-35 \text { yr) }\end{array}$ & 50 & $3.79 \pm 0.73$ & $6.55 \pm 1.14$ & $1.83 \pm 0.81$ \\
\hline $\begin{array}{l}\text { Group - } 4 \\
(36-40 \text { yr) }\end{array}$ & 36 & $3.91 \pm 0.73$ & $5.74 \pm 1.60$ & $1.86 \pm 0.84$ \\
\hline Total & 100 & $3.65 \pm 0.87$ & $6.09 \pm 1.52$ & $1.88 \pm 0.86$ \\
\hline
\end{tabular}

The results of ANOVA showed that there was a statistical significant difference in the variance of different components of somatotype of physically active Punjabi men of different age group (Table $3)$.

Table 3. Analysis of Variance (ANOVA) of Somatotype Physically Active Punjabi Men

\begin{tabular}{|c|c|c|c|c|c|c|}
\hline Variable(s) & & Sum of Squares & df & Mean Square & $\mathbf{F}$ & Sig. \\
\hline \multirow{2}{*}{ Endomorphy } & Between Groups & 22.114 & 3 & 7.371 & \multirow{2}{*}{13.161} & \multirow{2}{*}{.000} \\
\hline & Within Groups & 53.766 & 96 & .560 & & \\
\hline \multirow{2}{*}{ Mesomorphy } & Between Groups & 47.099 & 3 & 15.700 & \multirow{2}{*}{8.270} & \multirow{2}{*}{.000} \\
\hline & Within Groups & 182.256 & 96 & 1.898 & & \\
\hline \multirow{2}{*}{ Ectomorphy } & Between Groups & 11.767 & 3 & 3.922 & \multirow{2}{*}{5.971} & \multirow{2}{*}{.001} \\
\hline & Within Groups & 63.059 & 96 & .657 & & \\
\hline
\end{tabular}

Further, results of scheffe post-hoc showed that a statistical significant difference in the mean endomorphy component was found amongst Group 1 (20-25yrs) vs Group 3 (31-35yrs), Group 1 (20-25yrs) vs Group 4 (36-40yrs), Group 2 (26-30yrs) vs Group 3(31-35yrs) and Group 2(26-30yrs) vs Group 4(36-40yrs). In other words, we can say that endomorphy component of age group 1(2025yrs) and Group 2 (26-30) was less as compared to age group 3 and group 4 (Table.4). Essentially it was seen that endomorphy increased with age (Figure.1). Also, a statistical significant difference in the mean mesomorphy component was found amongst Group 1(20-25yrs) vs Group 3 (31-35yrs) and Group 3(31-35yrs) vs Group 4(36-40yrs). In other words, we can say that mesomorphy component of age group 1(20-25yrs) was less when compared with age Group 3(31-35yrs). But the mesomorphy component of Group 3(31-35yrs) was more than that of Group 4 (36-40yrs) (Table.4). 


\section{Journal of Exercise Science \& Physiotherapy Vol. 15 No. 1 (January to June) 2019 \\ ISSN: 0973-2020 (Print) I I OR Impact Factor =6.502 ISSN: 2454-6089 (Online)}

It meant that mesomorphy component in physically active Punjabi men increased with age upto 35 years and then decreased a little till 40 years (Figure.1). A statistical significant difference in the mean ectomorphy component was found amongst Group 1(20-25yrs) vs Group 3 (31-35yrs) and Group 1 (20-25yrs) vs Group 4(36-40yrs). In other words, we can say that ectomorphy component of age group 1(20-25yrs) was far more than that of age Group 3(31-35yrs) and Group 4(36-40yrs) (Table.4). In other words we can say that ectomorphy component decreased as the age progressed (Figure.1).

Table 4. Posthoc (Scheffe) Multiple Comparison of Somatotype of Physically Active Punjabi Men

\begin{tabular}{|c|c|c|c|c|}
\hline Dependent Variable & \begin{tabular}{|l|} 
(I) \\
age group
\end{tabular} & $\begin{array}{l}\text { (J) age } \\
\text { group }\end{array}$ & $\begin{array}{c}\text { Mean } \\
\text { Difference } \\
\text { (I-J) }\end{array}$ & Sig. \\
\hline \multirow{6}{*}{ Endomorphy } & \multirow{3}{*}{$20-25$} & $26-30$ & -.94367 & .125 \\
\hline & & $31-35$ & $-1.69167^{*}$ & .000 \\
\hline & & $36-40$ & $-1.82028^{*}$ & .000 \\
\hline & \multirow{2}{*}{$26-30$} & $31-35$ & $-.74800^{*}$ & .049 \\
\hline & & $36-40$ & $-.87661^{*}$ & .018 \\
\hline & $31-35$ & $36-40$ & -.12861 & .896 \\
\hline \multirow{6}{*}{ Mesomorphy } & \multirow{3}{*}{$20-25$} & $26-30$ & -1.22733 & .406 \\
\hline & & $31-35$ & $-2.54500^{*}$ & .001 \\
\hline & & $36-40$ & -1.59944 & .084 \\
\hline & \multirow{2}{*}{$26-30$} & $31-35$ & -1.31767 & .065 \\
\hline & & $36-40$ & -.37211 & .904 \\
\hline & $31-35$ & $36-40$ & $.94556^{*}$ & .027 \\
\hline \multirow{6}{*}{ Ectomorphy } & \multirow{3}{*}{$20-25$} & $26-30$ & .59300 & .573 \\
\hline & & $31-35$ & $1.35750^{*}$ & .003 \\
\hline & & $36-40$ & $1.13167^{*}$ & .022 \\
\hline & \multirow{2}{*}{$26-30$} & $31-35$ & .76450 & .068 \\
\hline & & $36-40$ & .53867 & .332 \\
\hline & $31-35$ & $36-40$ & -.22583 & .661 \\
\hline
\end{tabular}

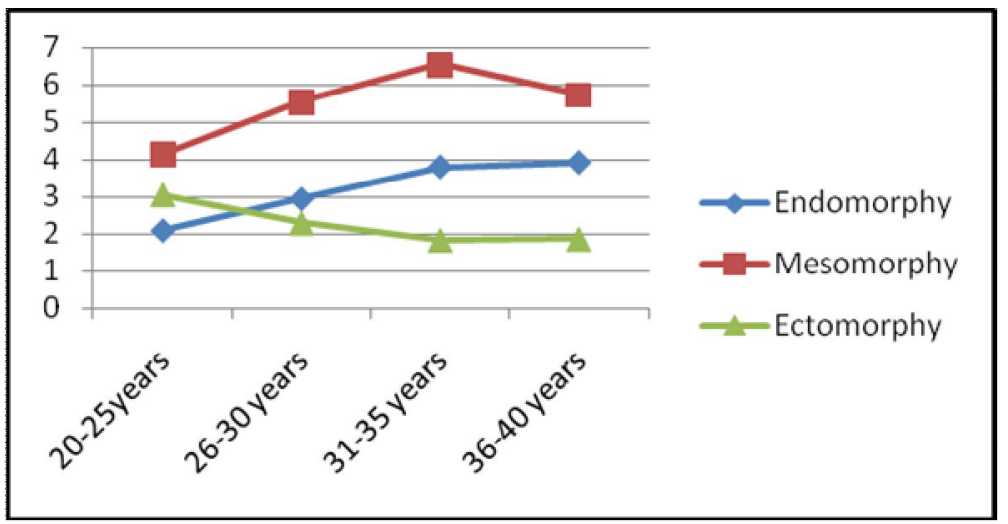

Figure 1. Pattern of change in somatotype of subjects with growing age 


\section{Journal of Exercise Science \& Physiotherapy Vol. 15 No. 1 (January to June) 2019 \\ ISSN: 0973-2020 (Print) I I OR Impact Factor $=6.502 \quad$ ISSN: 2454-6089 (Online)}

\section{Discussion}

The result of the present study show the somatotype of physically active Punjabi men is majorly endomorphic mesomorphs which is similar to the findings of another study by Koleva (2000) ( Table 2). The results also show mesomorphy to be dominant in all groups in comparison to other somatotype components (Table 2). Higher values of mesomorphy indicate strong musculo-skeletal development due to regular physical activity (Carter \& Heath 1990). In age Group 1(20-25yrs) the average body type was observed to be ectomorphic mesomorphs (Table 2) which meant that mesomorphy was dominant followed by ectomorphy. The ectomorphic component was highest in this age group in comparision to others. This may be because the younger population in this group who had lower body weight in comparison to height. Similar results were seen in another study (Rosique 1992; Gaur \& Singh 1997; Singh et.al 1998) Also, observation in bodytype of Group 2(26-30yrs) were balanced mesomorphs which meant that mesomorphy was dominant and ectomorphy and endomorphy was same. It was also seen that in age Group 3(31-35 yrs) \& Group 4(36-40yrs) the average body type was endomorphic mesomorphs; the endomorphy component was high during these years inspite of them being physically active. It may be derived that high levels of fat/adiposity had motivated these people to indulge in regular physical activity but the time and frequent of the exercise done by them may not be enough as reported by another study (Elgar et.al, 2005). While comparing the components of somatotype in different age groups we noticed a straight increase in the endomorphy till the age of $35 \mathrm{yrs}$ after which it almost stabilized, as observed in another study (Kalichmanb \& Kobyliansky 2006). Its is seen that the decrease in this component (endomorphy) occurs commonly in late adulthood and get replaced by ectomorphy (Herrera et.al 2004; Buffa et.al 2005). Our results also showed that mesomorphy increased significantly over the years till 35 years and then decreased later on. Few other studies also suggested that mesomorphy either stabilises or decrease as age progresses (Buffa R et.al, 2005).

\section{Conclusion}

In summary, the somatotype of physically active Punjabi men was found to be essentially endomorphic mesomorphs. Mesomorphy was high in all age Groups which can be because of muscle buildup with regular physical activity. An increasing trend in endomorphy and mesomorphy was seen from age Group 1 (20-25yrs) to Group 3 (31-35yrs) which later stablised or decrease in later years of life. Endomorphy which is charectorised by fat components was found to be high in middle age groups of 30-40 years leading to the conclusion that a change in frequency and intensity or type of physical activity may be needed in order to cut down the upper body fat. Lifestyle changes in diet may also help in the same.

\section{References}

Abercrombie, L. C., Sallis, J. F., Conway, T. L., Frank, L. D., Saelens, B. E., \& Chapman, J.E. 2008. Income and Racial Disparities in Access to Public Parks and Private Recreation Facilities. American Journal of Preventive Medicine, 34(1), 9-15.

Buffa R, Succa V, Garau D, Marini E, Floris G.2005. Variations of somatotype in elderly Sardinians. Am J Hum Biol 17:403-11.

Carter J. E. Lindsay.1970. Human Biology Vol. 42, No. 4 (December 1970), pp. 535-569

Elgar FJ, Roberts C, Moore L, Tudor-Smith C. 2005 Sedentary behaviour, physical activity and weight problems in adolescents in Wales. Public Health;119:518-24.

Gaur, R., \& Singh, R. P.1997. Age differences in somatotypes of Garhwali males 17-60 years of age. American Journal of Human Biology, 9(3), 285-290.

Health Carter Manual .2002. The heath-carter anthropometric somatotype instruction manual.

Heath, G. W., Parra, D. C., Sarmiento, O. L., Andersen, L. B., Owen, N., Goenka, S., Brownson, R. C. 2012. Evidence-based intervention in physical activity: lessons from around the world. The Lancet, 380(9838), 272-281. 


\section{Journal of Exercise Science \& Physiotherapy Vol. 15 No. 1 (January to June) 2019 \\ ISSN: 0973-2020 (Print) $\quad I_{2}$ OR Impact Factor $=6.502 \quad$ ISSN: 2454-6089 (Online)}

Herrera H, Rebato E, Hernandez R, Hernandez-Valera Y, Alfonso-Sanchez MA.2004.Relationship between somatotype and blood pressure in a group of institutionalized Venezuelan elders. Gerontology 2004;50:223-229.

Kalichman, L., \& Kobyliansky, E.2006. Sex- and age-related variations of the somatotype in a Chuvasha population. HOMO, 57(2), 151-162.

Koleva, M., Nacheva, A., \& Boev, M.2002. Somatotype and Disease Prevalence in Adults. Reviews on Environmental Health, 17(1).

Malina, R. M., Katzmarzyk, P. T., Song, T. M. K., Theriault, G., \& Bouchard, C.1997. Somatotype and cardiovascular risk factors in healthy adults. American Journal of Human Biology, 9(1), 11-19.

NFHS data 2005-06; Third National Family Health Survey. International Institute for Population Sciences, 2005-2006, Mumbai;

Rahmawati, N. T., Budiharjo, S., \& Ashizawa, K.2007. Somatotypes of young male athletes and non-athlete students in Yogyakarta, Indonesia. Anthropological Science, 115(1), 1-7.

Rajkumar, R. V. 2015. Endomorphy dominance among non-athlete population in all the ranges of body mass index. International Journal of Physiotherapy and Research, 3(3), 1068-1074

Reis, V. M., Machado, J. V., Fortes, M. S., Fernandes, P. R., Silva, A. J., Dantas, P. S., \& Filho, J. F. 2007. Evidence for Higher Heritability of Somatotype Compared to Body Mass Index in Female Twins. Journal of physiological anthropology, 26(1), 9-14.

Saranga, S. P. J., Prista, A., Nhantumbo, L., Beunen, G., Rocha, J., Williams-Blangero, S., \& Maia, J. A. 2008. Heritabilities of somatotype components in a population from rural Mozambique. American Journal of Human Biology, 20(6), 642-646.

Souza De Almeida, A., Rizzo, J., \& Batista, G. 2013. Somatotype analysis of physically active individuals. $J$ sports med phys fitness 2013;53:268-73

World Health Organization, 2011.Information sheet: global recommendations on physical activity for health 18 - 64 years old.

Conflict of Interest: None declared 